\title{
Real life ethics: autonomy versus duty of care
}

The Mental Capacity Act came into full force on 1 October 2007 and clarifies the law regarding advanced decisions (living wills), particularly in respect to the conditions that must be satisfied to make an advanced decision valid and the consequences of ignoring such decisions. These include prosecution under criminal law, claims for damages under civil law, and professional malpractice procedures. ${ }^{1}$ The act also emphasises the importance of acting in the best interests of an individual who lacks capacity, and respecting the right of competent individuals to make decisions for good reason, bad reason, or no reason, even if these decisions seem eccentric or unwise.

We ask whether a nation and a health service that are increasingly protocol-driven and rationed do in fact have the ability to allow the degree of patient choice that the Act demands? Should there be a ceiling to 'reasonable' autonomy? Is it possible that certain autonomous decisions will impose impossible restrictions on carers, health professionals, and society in general?

\section{CONSIDER THE FOLLOWING CASE HISTORY}

A 58-year-old lady of very independent mind wrote a living will in September 2005 after witnessing the death of her husband in an intensive care unit of the local hospital. She instructed any medical practitioners involved in the event of her suffering from a medical condition that would require resuscitation under no circumstances whatsoever to apply such resuscitation. This document was signed, dated, and witnessed by a legal executive and sealed in an envelope on which was written 'DO NOT TAKE ME TO [the local hospital]'. A copy of this letter was given to her GP and further copies were kept on display in prominent positions in the house and in her bedroom.

In early 2007 the patient developed evidence of a malignant melanoma. However, rather than seek medical advice she kept the matter a secret until the lesion was observed by a family member. Medical advice was then reluctantly sought, but she declined any sort of excision or biopsy for several weeks until the lesion was very obvious and local lymphadenopathy had developed. Finally she agreed to cosmetic surgery and a biopsy although it was explained to her that by this time this could only be palliative. Over the next few weeks she had several consultations with her GP and the situation and her prognosis were discussed very openly on each occasion. She requested euthanasia from her GP more than once. This was refused but the GP promised to honour her wishes and provide the best possible palliative care.

She became weaker but declined all offers of help and support from her family, district nurses, and MacMillan nurses. However, one morning she collapsed and suffered an epileptic fit. Much against her will, her elderly but fit parents, aged 81 and 83 years, moved in to care for her. An outpatient CT scan and MRI scan confirmed cerebral as well as hepatic metastases. Several weeks elapsed during which the patient became weaker yet retained full mental capacity. The GP visited regularly and on each occasion was asked by the patient how long it was likely to be before she died. This was invariably answered by explaining that there was no way of knowing the exact details or timings. Repeated attempts were made to explain the possibility of further convulsions as a terminal event but the patient was extremely reluctant to consider the mode of her death. She simply reiterated her desire to die as soon as possible and her absolute wish not to go to the local hospital.

Things changed dramatically one afternoon, only 2 hours after a routine house call by the GP, when she developed a further epileptic fit. Even though afternoon surgery was about to start, the GP attended immediately. The patient was in the throes of a generalised tonic-clonic convulsion and her parents, not surprisingly, were in a state of acute distress. The doctor administered $10 \mathrm{mg}$ of rectal diazepam, but this failed to arrest the convulsion. Due to her express wishes, which had been made so abundantly clear, an ambulance was not called initially. However, after 30 minutes and with no sign of the convulsion ceasing, an emergency call was put in. Because of the remote location of the patient's home and certain staffing issues among other professionals such as district nursing and palliative care colleagues it was not possible to obtain further supplies of diazepam until the ambulance arrived after a long delay. This meant that the patient had been in status epilepticus for more than 2 hours by the time a further $10 \mathrm{mg}$ of diazepam was given intravenously and an oxygen mask was applied by the paramedics. The patient became sedated although low level fitting continued.

Local protocol dictated that any 999 call should be taken to the nearest hospital, in this case the same hospital that the patient had so expressly stated she would not be taken to. A further 90 minutes was taken in telephone calls to managers in local hospitals, the ambulance service, district nursing service, palliative care professionals and others before permission was eventually granted for the patient to be taken to a hospital approximately 25 miles away, normally considered 'out of area'. She spent that night in the A\&E department before being transferred to a ward later the next day. She died a week later without regaining consciousness.

\section{DISCUSSION}

Cases like this are clearly rare, but the new Mental Capacity Act demands that we respect our patient's autonomy (particularly in respect to advanced decisions) and act in their best interests in the case of incapacity.

The patient had made it clear in written form that she did not want to be resuscitated nor to be admitted to the local hospital. However, she had been reluctant to discuss her mode of death. For the GP to act in the patient's best interests ${ }^{2}$ the primary concern was to stop the convulsions, even if hospital admission was required. How many GPs 


\section{The Terracotta Army}

would have been happy to leave a patient fitting at home in the presence of her elderly distressed parents? Is there a point at which the duty of care to a patient who is unconscious is superseded by the duty of care to others, in this case the elderly parents? Should there be a 'get-out clause' in advanced decisions for exceptional cases where distress to others may outweigh the need to respect the patient's wishes?

How does a doctor balance duty of care to one patient who will die very soon against the duty of care to other patients? In this case an entire afternoon was taken with this scenario and the doctor's evening surgery had to be taken by another doctor. The GP in this case is usually single handed. If the other doctor had not been available, what would have happened to all the other patients seeking medical attention that afternoon? Is it right for them to suffer while the GP is involved in one particularly complicated case?

The move towards patient autonomy and against 'doctor knows best' is undoubtedly a positive one. The Mental Capacity Act 2005 clarifies many of the points that were already present under common law. In interpreting the Act, we must be aware that in not all cases will it be clear that respecting patients' decisions and acting in their best interests are the same thing, and in this case, patient autonomy is the primary concern. However, we should also remember that as doctors we are a rationed resource which needs to be shared with all of our patients.

\section{Eleanor Brown and James Pink}

The authors would appreciate feedback or comments.

\section{REFERENCES}

1. Hempsons. Consent to treatment. A brief guide for the NHS. 2nd edn. London: Hempsons Solicitors, 2007. www.hempsons.co.uk/FileServer.aspx?oID $=396 \&$ IID $=0$ (accessed 6 Mar 2008).

2. General Medical Council: Withholding and withdrawing life-prolonging treatments: good practice in decision-making. London: GMC, 2006.

DOI: 10.3399/bjgp08X280038
It was $10.10 \mathrm{pm}$ when I entered the British Museum with my booking paper printed from the internet. I was due to see the Terracotta Army at 10.20 pm, my scheduled time; visits to the exhibition being arranged like this as booking is overwhelmed, with the Museum staying open until midnight on Thursdays and Fridays.

Just entering the museum at this time, with darkness outside and the entrance and hall virtually empty, is fascinating. But watching the exhibition is spectacular; you travel back to a time when human civilisation was at its height in Egypt with the Pharaohs, in Greece, in Italy with the Etruscans and the Romans.

Three hundred years BCE ... and you enter the mysterious atmosphere where the eyes of warriors, officials, generals, dignitaries, civil managers, musicians, craftsmen, horses, and birds look at you in silence; the silence of their more than 2000 years of life in the underground and afterlife in defence of, and serving, their Emperor.

Ying Zheng was born in China in 259 BCE. At the age of 13 he became King of Qin, one of the seven main states competing for dominance and at war with each other. Under his leadership, Qin conquered the other states using highly developed weapons, technology, and military strategy. After completing his campaign, the King of Qin declared himself Qin Shihuangdi: First Divine Emperor of the Qin.

To govern his empire, the First Emperor introduced reforms and enforced strict laws. He planned to join the walls of conquered states to create a great common wall, and built new roads and canals. Standard weights and measures, a single currency, and a universal writing system (very similar to the one used today) allowed him to govern more easily. He built more than 270 palaces in his capital city Xianyang, as a display of power and to house the rulers of the states he conquered.

The First Emperor wanted to govern forever and tried many potions to prolong his life. He also spent more than 30 years building his tomb complex, a palace where he could rule forever in the afterlife. At the centre of the complex (I read it twice at the panel ... unbelievable ... $56 \mathrm{~km}^{2}$ !) lay his tomb. In 1974 a farmer digging nearby found a terracotta head. He had discovered a pit of terracotta warriors.

Around 7000 terracotta soldiers have now been found buried in three pits outside the tomb, standing guard with their imposing height, of between 185 and $194 \mathrm{~cm}$, greater than that of the real population. This is now one of the world's most important archaeological sites and London hosted part of this incredible treasure of human history.

In the exhibition, warriors continue to ward the Emperor, musicians do their work, and birds also sing to their Emperor in the afterlife. The First August Divine Emperor died suddenly at the age of $49 \ldots$ but he is still alive and ruling his $56 \mathrm{~km}^{2}$ tomb complex. Computer images render only a faint idea of the inner complex of paths and corridors for different guardians, servants, warriors, horses, and carriages ... other corridors $\ldots$ and probably rivers of mercury.

However, nobody knows what treasures it contains, even with the most sophisticated technological methods it will not be possible to know without creating ruins for the next generations. So, rest peacefully, Qin Shihuangdi, rule quietly in your afterlife, continue to govern forever ... the terracotta army will guard you safely.

\section{Francesco Carelli}

DOI: 10.3399/bjgp08X280047 